Available online on 15.12.2020 at http://jddtonline.info
Open Access to Pharmaceutical and Medical Research

Open Access

Review Article

\title{
A Review on Carissa carandas: Traditional Use, Phytochemical Constituents, and Pharmacological properties
}

\author{
Saurabh Vilas Bhosale *, Rajkumar V. Shete, Vishal S Adak, Krishna Murthy \\ Dept. of Pharmacology, Rajgad Dnyanpeeths college of Pharmacy, Bhor, Pune, Maharashtra, India
}

\begin{abstract}
Carissa carandas $l$. (Karaunda) is a widely useful food and medicinal plant of India, Plant-based medicines play an important role in all cultures have been indispensable in maintaining health and combating diseases. Owing to the global trend towards better quality of life, there is a great claim for medicinal plants. Carissa carandas $l$. plant popularly used as a traditional medicinal plant over thousands of years in the Ayurvedic, Unani, and Homoeopathic system of medicine. The major bioactive elements, which impart the medicinal worth of herbs, are alkaloids, flavonoids, saponins, and huge amounts of cardiac glycosides, triterpenoids, phenolic compounds, and tannins. Traditionally, the whole plant and its parts were used in the treatment of various ailments. It contains several phytochemical constituents belonging to the terpenoids category. The root is attributed to bitter, stomachic; antidiarrheal, vermifuge, and ant anthelmintic properties. The medicinally unripe fruit is used as an astringent. The ripe fruit is taken as an antiscorbutic and therapy for nausea. The leaf decoction is appreciated in cases of alternating fever, diarrhea, oral inflammation, and earache. Also, Carissa carandas have showing a extensive range of evidence for its cardiotonic, hepatoprotective, free radical scavenging and xanthine oxidase inhibitory, histamine-releasing, antirheumatic, antibacterial, antiviral, and anticonvulsant activity. A higher gross heat value of this species indicates its higher potential to be used as a good fuel source.
\end{abstract}

Keywords: Carissa carandas , Phytochemical Constituents, Traditional Use, Pharmacological Properties.

Article Info: Received 07 Oct 2020; $\quad$ Review Completed 16 Nov 2020; $\quad$ Accepted 21 Nov 2020; Available online 15 Dec 2020

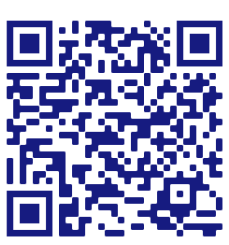

Cite this article as:

Bhosale SV, Shete RV, Adak VS, Murthy K, A Review on Carissa carandas: Traditional Use, Phytochemical Constituents, and Pharmacological properties, Journal of Drug Delivery and Therapeutics. 2020; 10(6-s):145-150 http://dx.doi.org/10.22270/jddt.v10i6-s.4443

*Address for Correspondence:

Bhosale Saurabh Vilas* Dept. of Pharmacology, Rajgad Dnyanpeeths college of Pharmacy, Bhor, Pune, Maharashtra, India

\section{INTRODUCTION}

Carissa carandas is a species of flowering plant in the dogbane family, Apocynaceae. It harvests berry-sized fruits that are commonly used as a condiment or preservative to Indian pickles and spices.The shrub Commonly name karonda (Devanagari: ) karamardaka(Sanskrit), Koromcha(Bengali), Christ's thorn (South India), vakkay (Telugu), kilaakkaai(Tamil) and Karja tenga(Asam). ${ }^{1}$ Its botanical name was in recent years altered to Carissa congesta Wight (syn. C. carandas Auct formerly widely shown as Carissa carandas. ${ }^{2}$ The famous biological activities reported are analgesic, anti-inflammatory, anti-pyretic, Cardiotonic, and histamine-releasing. The plant is also an alternative source of oil, hydrocarbon, and phytochemicals. ${ }^{3}$

\subsection{Description of Karaunda Tree: -}

Carissa carandas Linn. Is a dichotomously pronged evergreen shrub with a short branch and strong thorns in pairs, Carissa carandas Linn is an evergreen diffuse and spiny shrub occurring through the country. The plant is very valued for the Indian System of medicine mainly Ayurveda. It is used for alleviating Vata and pitta disorders. ${ }^{4}$ Species is a rank-growing, usually growing to 10 or $15 \mathrm{ft}$ (3-5 m) high, sometimes ascending to the tops of tall trees; and rich in white gummy latex. The branches, many and dispersal, forming dense masses, are set with sharp thorns, simple or forked, up to 2 in $(5 \mathrm{~cm})$ long, in pairs in the axils of the leaves. The leaves are evergreen, opposite, oval or eggshaped, 1 to 3 in $(2.5-7.5 \mathrm{~cm})$ long; dark-green, leathery, glossy on the upper surface, lighter green, and dull on the underside. The fragrant flowers are cylindrical with 5 hairy lobes that are twisted to the left in the bud instead of to the right as in other species. They are white, regularly tinged with pink, and borne in terminal clusters of 2 to 12 . The fruit, in clusters of 3 to 10 , is oblong, broad-ovoid or round, $1 / 2$ to 1 in $(1.25-2.5 \mathrm{~cm})$ long; has fairly thin but tough, purplishred skin turning dark-purple or closely black when ripe; smooth, glossy; enclosing very acid to equally sweet, often bitter, juicy, red or pink, juicy pulp, radiating flecks of latex. There may be 2 to 8 small brown seeds. The Karanda is common throughout much of India, Burma, and Malacca and dry areas of Ceylon; is rather commonly cultivated in these 
areas as a hedge and for its fruit, and the fruit is marketed in villages. The karanda was initial fruite in the Philippines in 1915.5 Fruits are rich source of iron and vitamin C, therefore, ethnomedical the fruits are used for curing anemia, as an astringent, antiscorbutic, and as a remedy for biliousness. Its leaf decoction is used in contradiction of fever, diarrhea, and earache, whereas roots help as a stomachic, vermifuge, remedy for itches, and insect repellent.

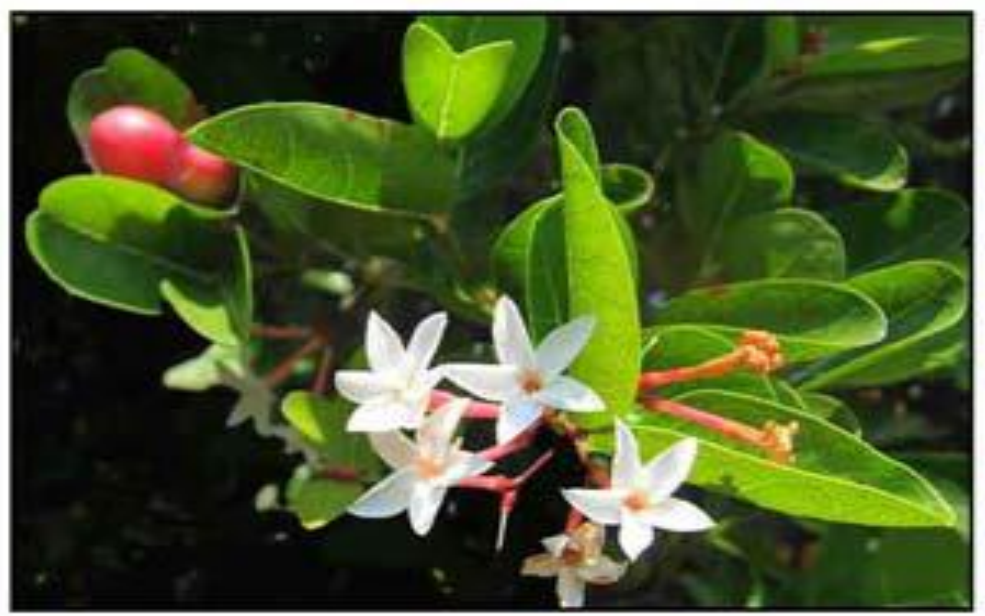

Flowers of Carissa carandus

\subsection{Cultivation: -}

Karaunda is a very hardy and drought-tolerant plant, it thrives well throughout the tropical and subtropical climates. Heavy rainfall and waterlogged conditions are not desirable. It can be grownup on a extensive range of soils including saline and sodic soils. Karaunda is commonly grown from seeds. Vegetative methods-air-layering and stem (hardwood) cuttings are feasible but not very common. Fresh seeds are sown in the nursery during august September. One- year old seedlings are transplanted. Airlayering is very successful in Karaunda. It can be performed at the beginning of the monsoon. Rooted coatings can be separated 3 months after layering. Karaunda plants grown as a protective hedgerow are hardly fertilized. Manuring, however, is used as $10-15 \mathrm{~kg}$ well-rotten farmyard manure or compost/plant and should be applied before flowering. Irrigation: The water requirement of Karonda is very low. Irrigation after planting and manuring is essential. Plantation once established does not need much water. The fruits grow from July to September in north India. Karaunda fruits mature 100-110 days after fruit set. At this stage, fruits develop their natural color. Fruits ripen after this stage, taking about 120 days (after fruit set) when they become soft and attain dark purple/maroon/ red color. After the packing of fruits, they are kept in shade. Fruits collected at maturity can be stored for a weak at room temperature. Fruits can be preserved/stored for 6 months in SO2 solution $(2,000 \mathrm{ppm}) .^{7}$

\subsection{Taxonomy}

Kingdom: Plantae
Order: Gentianales

Class: Angiosperms

Family: Apocynaceae

Sub-class: Eudicots

Superorder: Asterids

Genus: Carissa

Species: carandas

\section{PHYTOCHEMICAL CONSTITUENTS}

These activities of $C$. carandas were reported from the crude extract, their different fractions, and isolates from fruits, leaves, and roots. Roots also reported to contain volatile principles including 2-acetyl phenol, lignan, carinol, sesquiterpenes (carissone, carindone), lupeol, $\beta$-sitosterol, $16 \beta$-hydroxybetulinic acid, $\alpha$-amyrin and $\beta$-sitosterol glycoside, and des- $\mathrm{N}$ methylnoracronycine, an acridone alkaloid 8 , 9. Fruits of $C$. carandas were stated to contain carisol, an epimer of $\alpha$-amyrin, linalool, $\beta$ caryophyllene, carissone, carissic acid, carindone, ursolic acid, carinol, ascorbic acid, lupeol, and $\beta$ sitosterol 11 The crude methanolic extract of leaves of Carissa carandas was tested for its different chemical groups as alkaloids, flavonoids, gums, reducing sugars, saponins, steroids, and tannins 11,12 . flowers of C. carandas are volatile oil like myrcene, limonene, camphene, carene, dipentene, farnesol, nerolidol, $\alpha$ terpeneol, citronellal, $\beta$-ionone, linalool, and geranyl acetate. ${ }^{13}$ 


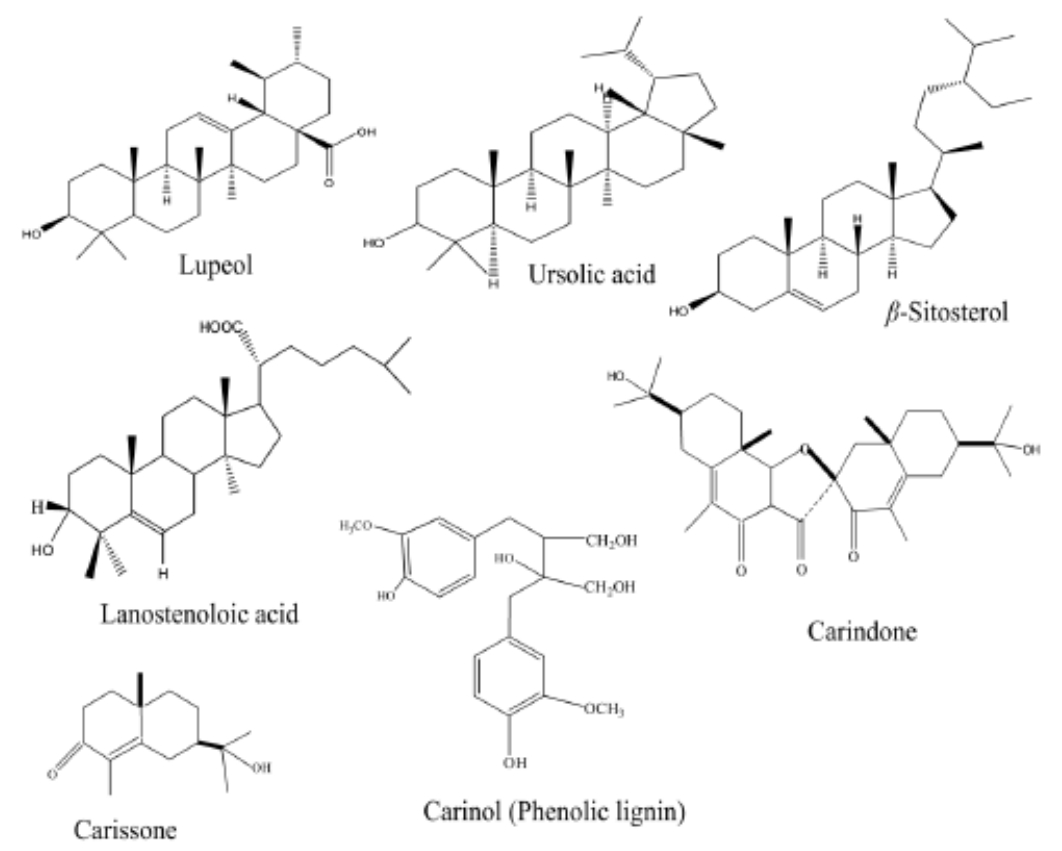

Phytochemical constituents of $C$. carandas.

\section{TRADITIONAL USES}

Carissa carandas has been used from immemorial time to yet traditionally to treat different human ailments. C. carandas is the best-known associate of the genus as it has been used as a old-style remedial shrub over thousands of centuries in the ayurvedic system of medicine as it is practiced on the Indian sub-continent. Thus, traditional uses of $C$. carandas are well established. The root is credited with bitter, stomachic, antidiarrhoeal, and antianthelmintic properties. The ripe fruits are utilized in curries, tarts, puddings, and chutney. When only slightly under-ripe, they are made into jelly. ${ }^{1}$ Green, sour fruits are made into pickles in India. With skin and seeds removed and seasoned with sugar and cloves, they have been popular as a substitute for the apple in tarts. The unripe fruit is used therapeutically as an astringent. The ripe fruit is taken as an antiscorbutic and remedy for nausea. The fruits have been employed as agents in tanning and dyeing British residents in India undoubtedly favored the karanda as being reminiscent of gooseberries. Karanda leaves have furnished food for the tussar silkworm. The leaf decoction is valued in cases of intermittent fever, diarrhea, oral inflammation, Antibacterial activity, and earache. ${ }^{14}$ A paste of the pulverized roots serves as a fly repellent. The root is employed as a bitter stomachic and vermifuge and it is an ingredient in a remedy for itches. The roots of Carissa carandas contain salicylic acid and cardiac glycosides causing a slight decrease in blood pressure. The white or yellow wood is hard, smooth, and useful for molding spoons, combs, household utensils, and miscellaneous products of turnery. It is sometimes burned as fuel .5, 15

\section{PHARMACOLOGICAL ACTIVITIES}

Carissa carandas are known to possess a wide range of phytochemicals in the plant parts (roots, leaves, stem, and fruit) that give the plant tremendous medicinal value. These active ingredients give the plant medicinal value. The pharmacological significance of the plant has been assessed by various workers through in vitro and in vivo approaches.

\subsection{Antioxidant and cytotoxic property: -}

Yakut Bint-e-Sadek et al studied was to determine the ISSN: 2250-1177 different phytochemical compounds of Carissa carandas leaf extracts, their antioxidant properties, antimicrobial activities, and cytotoxic potentials. Ethanolic and n-hexane extracts from the leaves of the Carissa carandas they were used. The results showed significant antioxidant activities compared to ascorbic acid and in DPPH eliminating free radicals with IC50 of $1,292 \mu \mathrm{g} / \mathrm{ml}$ and $1,824 \mu \mathrm{g} / \mathrm{ml}$ of ethanolic extract and n-hexane extract. Extract $\mathrm{H}_{2} \mathrm{O}_{2}$ removal activities were found to be better than the standard, which had higher $\mathrm{IC}_{50}$ values than ascorbic acid. Total antioxidant activity and the total phenolic content was also determined. The leaf extracts showed no antimicrobial activity. through the disc diffusion method using extracts ranging from 0.1 to $400 \mu \mathrm{g} /$ disc compared kanamycin disk $30 \mu \mathrm{g} /$ disk. ${ }^{2}$

Vijay Kumar et al demonstrated free radicals drilling capabilities of petroleum ether and methanolic extracts of seeds, fruits, and leaves. Phytochemical analysis of extractions of different parts of $C$. Carandas was performed followed by free radical extraction capacity using the frap method. The results of reducing the power capacity of different extracts were compared concerning each other through statistical analysis applying one-way ANOVA. Exploratory of phytochemical content in petroleum ether and methanolic extracts of leaves, fruits, and seeds of Carissa carandas extract found uniquity of components including alkaloids, phenolics, flavonoids, oils and fats, saponins and tannins. Statistical analysis showed that the methanolic extract from the leaves was a strong free radical scavenger among all other extracts studied. The specific results that qualitative phytochemistry selection carried out in the petroleum ether and the methanolic extracts of leaves of $c$. carandas, fruits, and seed extract confirmed the presence of some bioactive compounds (alkaloids, phenolic compounds, flavonoids, tannins, saponins, oils, and fats) in its different parts. Carissa's carandas methanolic extract of the leaves had the highest free radical scavenging activity compared to the petroleum ether fruit extract and seed. The radical removal potential of plants compares highly to that of the standard, ascorbic acid. The methanolic extract from the leaves of Carissa carandas had the highest elimination of free radicals activity compared to the fruit and seed oil ether extract. 16 
Marina Khatun et al studied was designed to explore the antioxidant, cytotoxic and antineoplastic properties of the leaf extract of Carissa carandas Linn. a traditional medicinal plant. Methanol extract from Carissa carandas leaves (MELC) was applied in DPPH and ABTS experiments to determine its antioxidant activity. In vitro, the cytotoxic effect of MELC against colon adenocarcinoma cell lines (SW-480 and SW48) while their antineoplastic property was tested in vivo against Ehrlich's carcinoma of ascites (EAC). The DPPH and ABTS tests revealed the antioxidant activity of MELC with IC50 $10.5 \pm 1.2$ and $1.75 \pm 0.3 \mu \mathrm{g} / \mathrm{ml}$ that was comparable to l-ascorbic acid. In vitro cytotoxic studied, MELC reduced the viability of adenocarcinoma cells in a dose-dependent manner, and in vivo administration of MELC $(25 \mathrm{mg} / \mathrm{kg})$ resulted in a significant decrease $(p<0.05)$ in the viable EAC cell count, thus increasing the lifespan of EAC cell-bearing mice. Restoration of hematological parameters such as red blood cells (RBC), hemoglobin, and white blood cells (WBC) was also observed at normal levels in MELC-treated mice. Further, treatment with MELC-induced apoptosis of EAC cells as seen in the DAPI fluorescence microscopic view (4. 6diamidino-2-phenylindole) cells were stained and MELCtreated cells expression of p53 gene was also increased relative untreated EAC controlled. Furthermore, MELC was rich in polyphenol content and its GC-MS chromatogram confirmed the presence of some compounds, all of which showed anticancer and cytotoxic activities in previous studies. In a word, this studied supports the use of Carissa carandas in traditional medicine and highlights then they need to further explore the potentials of MELC as an antineoplastic agent. ${ }^{17}$

\subsection{Anti-inflammatory and antipyretic activity: -}

Manoranjan Hati et al evaluated the anti-inflammatory and antipyretic activity of methanol extract of $C$. carandas $l$. leaf. The extract was evaluated by phytochemicals screening, which indicated the presence of steroids, glycosides, flavonoids, tannins, terpenoids, and carbohydrates the antiinflammatory property was evaluated by using different models such as carrageenan, histamine, and dextran induced hind leg edema in Wister albino rats. Extract at a dose of 200 $\mathrm{mg} / \mathrm{kg}$. body weight exhibited maximum inhibition of inflammation, i. e. $72.10 \%, 71.90 \%$, and $71.80 \%$ at the end of 3 hours with histamine, dextran, and carrageenan-induced rat paw edema respectively. The antipyretic activity was evaluated by brewer's yeast-induced pyrexia in albino rats. Extract at a dose of 100 and $200 \mathrm{mg} / \mathrm{kg} \mathrm{p}$. o., showed a significant reduction in yeast-induced elevated temperature at a dose-dependent manner, and the effect also lasted up to 4 hours after administration of the drug. The results of this studied. Indicated that the methanol extract from the leaves of c. carandas l. had important anti-inflammatory properties and antipyretic activities in rodent models. ${ }^{18}$

Bhaskar and Balakrishnan et al reported pain relievers, significant anti-inflammatories, and antipyretic activities of ethanol and aqueous extracts of roots of $C$. Carandas in rodent models. Ethanol and aqueous C. carandas root extracts exhibited a significant amount $(p<0.01)$ analgesic, anti-inflammatory, and antipyretic activities at doses 100 and $200 \mathrm{mg} / \mathrm{kg}$ of body weight. Observed higher inhibition percentage of abdominal constriction $(72.67 \%)$ ethanol $C$. carandas extracts at a dose of $100 \mathrm{mg} / \mathrm{kg}$ body weight in pain reliever exercise. Besides, ethanol and aqueous extracts of $C$. carandas reduced the formation of carrageenan-induced edema after 2 hours. ${ }^{19}$

\subsection{Anti-diabetic activity: -}

Prakash R. Itankar et al. evaluated the anti-diabetic potential of the plant by screening methanol extracts and their fractions in alloxan Diabetic rats. He reported that methanol extract and its ethyl acetate soluble fraction is significantly reduced Blood glucose levels per oral dose of $400 \mathrm{mg} / \mathrm{kg}$ after 24 hours Compared with diabetes control. Polyphenol content of methanol extract the ethyl acetate soluble fraction was found to be $15.8 \pm 1.2 \mathrm{mg}, 18.55 \pm 0.34 \mathrm{mg}$ (gallate equivalent / g extract), while flavonoids contents of the two extracts are $2.92 \pm 0.03 \mathrm{mg}$ and $1.534 \pm 0.30 \mathrm{mg}$ (Rutin equivalent / g extract). Concluded that the anti-diabetic potential of ethyl acetate fraction for methanol extract is partly purified by fractional distillation, Leading to an increased degree of polymerization, and Secondary metabolites. ${ }^{20}$

Gaurav et al. evaluated the effects of aqueous extracts of Carissa carandas on alloxan-induced and normoglycemic Wister rats. Three doses of extract $(250 \mathrm{mg} / \mathrm{kg}$; oral 500 $\mathrm{mg} / \mathrm{kg}$ and $1000 \mathrm{mg} / \mathrm{kg}$.) and found that $250 \mathrm{mg} / \mathrm{kg}$ extract of Carissa carandas line. did not show any major changes in blood glucose levels compared to untreated controls. The doses of 500 and $1000 \mathrm{mg} / \mathrm{kg}$ extract showed a significant $(p<0.5)$ reduction in blood glucose levels after 4 , 8 , and 24 hours. In rats with normal blood sugar, the dose of the extract was significant at $1000 \mathrm{mg} / \mathrm{kg}(\mathrm{p}<0.05)$ 8-hour and 24-hour blood glucose levels. The dosage of the extract had shown significant $(\mathrm{p}<0$. 05) hypoglycemic and antihyperglycemic effects in Wister rats. ${ }^{21}$

\subsection{Anti-convulsant activity: -}

Hegde et al. Anti-convulsant effect of the ethanolic extract of C. carandas roots $(100,200$, and $400 \mathrm{mg} / \mathrm{kg}$, i.p.) has been investigated on electrically, and chemically induced seizures. The extract $(100-400 \mathrm{mg} / \mathrm{kg})$ significantly reduced the duration of seizures induced by maximal electroshock. However, only 200 and $400 \mathrm{mg} / \mathrm{kg}$ of the extract conferred protection $(25 \%$ and $50 \%$, respectively) on the mice. The same doses also protected animals from pentylenetetrazole induced tonic seizures and significantly delayed the onset of tonic seizures produced by picrotoxin and N-methyl-dlaspartic acid. The extract did not affect bicuculline-induced seizures. Observed the anticonvulsant effects of the ethanolic root extract of $C$. carandas via nonspecific mechanisms since the extract reduced the duration of seizures produced by maximal electroshock as well as delayed the latency of seizures produced by pentylenetetrazole, and picrotoxin. ${ }^{8}$

\subsection{Anti-cancerous activity and antioxidant potentials: -}

David M and Karekalammanavar G et al: Fruit extracts of $C$. carandas in chloroform, n-hexane, and methanol were tested for their anticancer activity in lung cancer cells and human ovarian carcinoma cells. All the extracts showed excellent anticancer activity. Besides, the anticancer and antioxidant potentials of the extracts. were analyzed for unusual antioxidant enzymes such as catalase, dismutase, superoxide, glutathione-s-transferase, and glutathione in MCF-7 cancer lines. This study exhibited important antioxidant activity and fortification of cell death in the MCF-7 cell line pretreated with C. carandas extracts. Researchers suggested the anticancer potential value of this medicinal plant fruit for the future development of therapeutic drugs ${ }^{22}$. Furthermore, in vitroanti Cancer studies showed that aqueous ethanolic fruit extract (ESA) induces cytotoxicity at $800 \mu \mathrm{g} / \mathrm{ml}$ in HeLa cancer cells maintained in Dulbecco's modified Eagle's medium (DMEM). The study concluded that regular daily intake Suggested Diet Fruits with Reduced Risk of Infection diseases and cancer . 23

\subsection{Hepatoprotective activity: -}

Hegde K, Joshi A B et al. : Ethanolic extract of roots of C. 
carandas (100, 200 and $400 \mathrm{mg} / \mathrm{kg}$, p.o.) showed significant hepatoprotective activity against paracetamol-induced and carbon tetrachloride hepatotoxicity by declining the activities of serum marker lipid peroxidation and bilirubin and significantly amplifying the levels of glutathione, uric acid, superoxide dismutase and protein. Carissa carandas root extract shows Hepatoprotective activity. ${ }^{24}$

\subsection{Cardiovascular activity: -}

Vohra M M and De N N et al.: The ethanolic extract of roots of C. carandas exhibited cardiotonic activity and lowered the blood pressure. The cardiac activity of the plant has been recognized as the presence of water-soluble glucosides known as odoroside. The dose $45 \mathrm{mg} / \mathrm{kg}$, i.p. caused a significant (50.75\%) decrease in arterial blood pressure $(\mathrm{P}<0.001)$, and the frequency of heart rate was also reduced significantly. It was also found that the ethanol extract of the plant possess a potent hypotensive effect in normal rats. 25

\subsection{Antimicrobial activity:}

The ethanolic extract of the fruit has powerful antibacterial action against different test bacteria like B. subtillis, $\mathrm{S}$. aureus, E. coli, S. faecalis, S. Typhimurium, and P. aeruginosa. Moreover, the ethanolic extract has also shown extensive anticandidal action.$^{26}$

\subsection{Anthelmintic activity: -}

Mishra C K et al: The different concentrations (50, 100, and $150 \mathrm{mg} / \mathrm{ml}$ ) of fruits extract C. carandas in solvent petroleum ether (60-80), ethanol and chloroform were evaluated in vitro anthelmintic potency on Pheretimap osthuma by determination of time of paralysis and time of death of the worm. The Piperazine citrate $(15 \mathrm{mg} / \mathrm{ml})$ was used as the standard drug. It was concluded that the fruits extract of $\mathrm{C}$. carandas causes earthworm paralysis and also its death after some time .27

\subsection{Antibacterial activity: -}

S. Verma, H.S. Chaudhary et al.: The dichloromethane and toluene extract of the leaves of $\mathrm{C}$. carandas showed better results against Staphylococcus aureus and Klebsiella pneumonia. The fruit extract of C. carandas in dichloromethane exhibited high antibacterial activity against E. coli. The fruit extract in ethyl acetate showed the best result against all the strains of bacteria. 28

\subsection{Neuropharmacological and diuretic activities; -}

Ripan Saha et al: The crude methanolic extracts of leaves of Carissa carandas Linn. were evaluated for its neuropharmacological and diuretic activities. The extract of Carissa carandas leaves also potentiated the pentobarbitalinduced sleeping time in mice and decreased the open field score in the open field test, decreased the number of holes crossed from one chamber in the hole cross test, and decreased the head dip responses in hole board test. The diuretic activity was proved by the electrolyte loss ratio $(\mathrm{Na}+/ \mathrm{K}+$ excretion ratio was 1.46 and 1.43 at the doses of 200 and $400 \mathrm{mg} / \mathrm{kg}$ respectively) as that of the standard diuretic furosemide (1.48). 29

\subsection{Antimalarial activity: -}

Bapna S et al: Methanolic and aqueous extracts of leaf, stem bark, and fruit of the plant $C$. carandas, tested against Plasmodium falciparum 3D7 strain. Both aqueous and methanolic extract exhibited promising antimalarial activity (IC50 ranged between 41.52 and $100 \mu \mathrm{g} / \mathrm{mL}$ ) and (IC50 ranged between 13.57 and $69.63 \mu \mathrm{g} / \mathrm{mL}$ ). The cytotoxicity of the host cell was also analyzed on the Madin-Darby canine kidney cell line utilizing the MTT test that exposed no cytotoxicity in the maximum dose tested. 30

\section{REFERENCES}

1) Singh A, Uppl GK, A Review on Carissa carandas - phytochemical, ethno-Pharmacology and Micropropagation as conservation stratergy, Asian Journal of Pharmaceutical and Clinical Research, 2015; 8(3):54-60.

2) Bint-e-sadek Y, Choudhary $N$ and Shahriar $M$, Biological Investigation of the leaf extract of Carissa carandas, International Journal of Pharmacy Research and Technology, 2013; 5(2):97-105

3) Maheshwari R, Sharma A, and Verma D, Phyto-therapeutic significance of karaunda, Bulletin of Environment, Pharmacology and Life Science, 2012; 1(12):34-36.

4) Sawant RS, Comparative studies of Phytochemical screening of Carissa carandas liin., Asian Journal of Plant Science and Research, 2013; 3(1):21-25

5) Devmurari V, Shivanand P, Goyani MB, Vaghani S, Jivani NP, A Review: Carissa Congesta Phytochemical constituents, Traditional Use and Pharmacological propertices, Pharmacological Review, 2009; 3(6):375-377.

6) Malik SK, Chaury R, Dhariwaln OP, Bhandari DS, Genetic Resource of Tropical Underutilized Fruits in India, National Bureau of Plant Genetic Resources, 2010:178.

7) Maheshwari R, Sharma A, and Verma D, Phyto-therapeutic significance of karaunda, Bulletin of Environment, Pharmacology and Life Science, 2012; 1(12):34-36.

8) Hedge K, Thakker SP, Joshi AB, Shastry CS, Chandrashekhar KS, Anticonvalsant activity of Carissa carandas Linn root extract in experimental mice, Tropical Journal of Pharmaceutical Research, 2009; 8(3):117-125.

9) Rastogi RC, Vohra MM, Rastigi RP, Dhar ML, Studies on Carissa carandas Linn. Part I. Isolation of cardiac activity Principle, Indian Journal of Chemistry, 1966; 4(5):132.

10) Shailajan S, Sayad N, Tiwari B, Biomarker Based Quality Control Method for Carissa carandas Linn. Fruits Using HPTLC Tech, International Journal of Resent Advances in Pharmaceutical Research, 2013; 3(2):33-37.

11) Evans WC, Trease and Evan's Textbook of Pharmacognosy $13^{\text {th }}$ Ed Cambidge University Press, London, 1989:546.

12) Saha R, Hossain L, Utpat B, Ahmed AR, Neuropharmacological And Diuretic activities of Carissa carandas linn., Leaf Pharmacology online, 2010; 2:320-327.

13) Rana S, Prakash V, Sagar A, Review on medicinal and antioxidant properties of some medicinal plants, Journal of Drug Delivery and Therapeutic, 2016; 6:1-6.

14) Agarwal T, Sing R, Shukla AD, Waris I, In vitro study of antibacterial activity of Carissa carandas leaf extract in rats, Journal of Pharmaceutical, Chemical and Biological Science, 2012; 1:18-25.

15) Addis G, Abebe D, Urga K, A Survey of traditional medicinal plant in shirka district, Arsizone Ethiopian Pharmacutical Journal, 2001; 19:30-47.

16) Kumar V, Tarpada P, Sadariya K, Goswami S, Comparative Phytochemical and Antioxidant activity of methanol And Petroleum Ether Extract of Carissa carandas leaves, fruit and seed, Vivechan International Journal of Research, 2017; 8(2):7075.

17) Khatun M, Habib MR, Rabbi MA, Amin R, Islam MF, Nurujjaman M, Karim MR, Rahman MH, Antioxidant, Cytotixic and Antineoplastic effect of Carissa carandas Linn. Leaves, Experimental and Toxicology Pathology, 2017 :465-476.

18) Hati M, Jena BK, Nayak AK, Evaluation of anti-inflammatory and anti-pyretic activity of Carissa carandas leaf extract in rat, Journal of Pharmaceutical Chemical and Biological Sciences, 2014; 1(1):18-25.

19) Bhaskar VH, Balkrishnan N, Analgesic, Anti-inflammatory and antipyretic activity of pergularia daemia and Carissa carandas , Journal of Pharmaceutical Sciences, 2009; 17(3):168-174.

20) Itankar PR, Lokhande SJ, Verma PR, Arora SK, Antidiabetic potential of unriped Carissa carandas linn fruit extract, Journal of Ethnopharmacology, 2011; (135):430-433.

21) Swami G, Nagpal N, Rahar S, Singh P, Porwal A, Nagpal MA, And Kopoor R, Effect of Aqueous extract of Carissa carandas linn on blood glucose level of normoglycemic and alloxan induced diabetic wister Rats, International Journal of current 
Pharmaceutical Research, 2010; 2(3):65-67.

22) Dua D, Srivastav NS, Anti-cancerous and antioxidant potential of aqueous extracts of Annona reticulata, Podophyllum peltatum, Psidium guajava, Ananas comosus, Carissa carandas on MCF-7 cancer cell line, International Journal Integr Science Innovation Technology Science, 2013; 2(4):15-19.

23) David M and Karekalammanavar G. Spectrographic analysis and in vitro study of antibacterial, anticancer activity of aqueous ethanolic fruit extract of Carissa carandas , Journal of Advanced Scientific Research, 2015; 6(3):10-13.

24) Hegde $K$, Joshi AB, Hepatoprotective effect of Carissa carandas Linn root extract against $\mathrm{CCl} 4$ and paracetamol induced hepatic oxidative stress, Indian Journal of Experimental Biology, 2009; 47(8):660-7.

25) Vohra M M, De N N, "Comparative cardiotonic activity of Carissa carandas $\{L\}$. and Carissa spinarum $\{A\}$, Indian Journal of Medical Research, 1963; 51(5):937-940.
26) Alikeramat SS, Malek MA, Islam K, Salamatullah K, "The food values of indigenous foods Institute of food and Nutrition, Dhaka University, Bangladesh, $1977: 15$.

27) Mishra CK, Sasmal D, Shrivastava B, An in vitro evaluation of the anthelmintic activity of unripe fruits extract of Carissa carandas Linn, International Journal of Drug Devlopment and Research, 2012; 4(4):393-7.

28) Verma S, Chaudhary HS, Effect of Carissa carandas against Clinically Pathogenic bacterial strains, Journal of Pharmacy Research. 2011; 4: 3769-3771.

29) Saha R, Hossian L, Neuropharmacological and Diuretic activity of Carissa carandas Linn. Leaf, Pharmacologyonline, 2010; 2: 320327.

30) Bapna S, Ramaiya M, Chowdhary A, Antimalarial activity of Carissa carandas Linn. against Plasmodium falciparum, Jouranal of Antimicrobial Photon, 2013; 128: 246-50. 